\title{
Aberrant miRNAs expressed in HER-2 negative breast cancers patient
}

\author{
Cornelia Braicu ${ }^{1 *}$, Lajos Raduly ${ }^{1 \dagger}$, Gabriela Morar-Bolba ${ }^{2,3}$, Roxana Cojocneanu', Ancuta Jurj ${ }^{1}$, Laura-Ancuta Pop ${ }^{1}$, \\ Valentina Pileczki ${ }^{1}$, Cristina Ciocan ${ }^{4}$, Alin Moldovan ${ }^{4}$, Alexandru Irimie ${ }^{5,6}$, Alexandru Eniu' ${ }^{7}$ \\ Patriciu Achimas-Cadariu ${ }^{5,6}$, Angelo Paradiso ${ }^{7}$ and loana Berindan-Neagoe ${ }^{1,4,8}$
}

\begin{abstract}
Background: Breast cancer is a highly heterogeneous pathology, exhibiting a number of subtypes commonly associated with a poor outcome. Due to their high stability, microRNAs are often regarded as non-invasive cancer biomarkers, having an expression pattern specific for their 'cell of origin'.

Method: Triple negative breast cancer (TNBC: ER-, PR-, Her-2-) and double positive breast cancer (DPBC: ER+, PR+, Her-2) miRNA expression patterns were obtained by analysis of the TCGA (The Cancer Genome Atlas) data, followed by PCR-array analysis on plasma samples from 20 TNBC patients, 14 DPBC patients and 11 controls.

Results: Three downregulated and nine upregulated miRNAs were obtained from the TNBC analysis. Five overexpressed miRNAs were identified in the DPBC group. Four of the dysregulated miRNAs (miR-10a, miR-125b, miR-210 and miR-489) were common for both groups. The cluster miR-17-92 (miR-17, miR-20a, miR-20b, and miR93), along with miR-130, miR-22 and miR-29a/c, were found to differentiate between TNBC and DPBC. A panel of five transcripts (miR-10a, miR-125, miR-193b, miR-200b and miR-489) was validated in a new set of plasma samples. The overlapping of TCGA and plasma profiling data revealed miR-200b, miR-200c, miR-210 and miR-29c as common signature. MiR-200b was validated on additional normal and tumor tissue samples. The expression level of this transcript from the TCGA data was correlated with lung and bone metastatic genes.

Conclusion: The miR-200b presents a great potential for the future advancements in the diagnostic/prognostic and therapeutic approach of TNBC, along with other coding or non-coding transcripts. However, this needs to be further integrated in a regulatory network that acts in conjunction with other markers that affect the patients' prognosis or response to therapy.
\end{abstract}

Keywords: Triple negative breast cancer, Double positive breast cancer, Plasma miRNA

\section{Background}

Breast cancer $(\mathrm{BC})$ is the most common malignant pathology affecting women worldwide [1-3]. As BC accounts for an increasing number of deaths each year, efforts are being made to develop more efficient methods for early diagnosis, stratification and prediction of therapy response. The complexity of this disease comes from the diversity of environmental factors along with various inhered or acquired genomic, transcriptomic or

\footnotetext{
* Correspondence: braicucornelia@yahoo.com; cornelia.braicu@umfcluj.ro

${ }^{+}$Cornelia Braicu and Lajos Raduly contributed equally to this work.

${ }^{1}$ Research Center for Functional Genomics, Biomedicine and Translational

Medicine, "Iuliu Hatieganu" University of Medicine and Pharmacy,

Cluj-Napoca, Romania

Full list of author information is available at the end of the article
}

proteomic alterations [4]. In general, BC is classified based on the expression levels of estrogen receptor (ER), progesterone receptor (PR) and human epidermal growth factor receptor 2 protein (HER-2). Triple negative breast cancer (TNBC) represents about $15-20 \%$ of BC cases [5, 6], and is characterized by the absence of ER, PR and Her-2 proteins $[2,4,5]$. This $\mathrm{BC}$ subtype poses major clinical challenges due to the lack of specific diagnostic/prognostic biomarkers and the failure of standard therapy to provide a targeted effect $[2,6-8]$.

MicroRNAs (miRNAs) are short noncoding RNAs of about 19-25 nucleotides in length [9-11]. MiRNA profiling studies have identified specific miRNA signatures in a wide range of cancer types [12-14]. These

(C) The Author(s). 2018 Open Access This article is distributed under the terms of the Creative Commons Attribution 4.0 International License (http://creativecommons.org/licenses/by/4.0/), which permits unrestricted use, distribution, and 
transcripts can either be overexpressed (oncomiRs) or underexpressed (tumor suppressor miRs) $[4,11,15,16]$. These alterations are specific for each malignancy, including various $B C$ subtypes $[4,5,7,9,15-18]$. Thereby, circulating miRNAs are potential biomarkers in the case of numerous diseases [19], such as $B C$ [15, 20-22]. The studies undertaken to prove the causative effect of miRNA first perform a general profiling of clinical samples, then are followed by controlled experiments [22-26]. Still many questions remain regarding the exact mechanisms, biological functions, and clinical implication of miRNAs in the BC subtypes [11, 17, 21].

The Cancer Genome Atlas (TCGA) is a large database of sequencing results generated from studies involving genome analysis in a rigorous and consistent manner [27]. This allowed us to perform a direct comparison between the TCGA data and the results from our PCR-array plasma profiling study of TNBC and DPBC. We evaluated a panel of miRNAs related to $\mathrm{BC}$ and we identified the most specific miRNAs for TNBC and DPBC. The validation was done in a new independent patient cohort with the help of qRT-PCR technology. Furthermore, by overlapping the miRNA patterns, we identified either common or specific miRNA signatures for the two selected subtypes of Her-2 negative BC. Based on the expression level of the transcripts, miRNAs survival curves were generated. The results revealed the prognostic potential of some miRNAs, as well as their interdependence with some metastasis related genes.

\section{Methods}

\section{TCGA miRNA expression pattern evaluation}

We downloaded level 3 TCGA data from the University of California Santa Cruz cancer genomics data portal in the form of data matrices documenting patterns of miRNA expression for 112 TNBC tissue samples, 358 DPBC tissue samples, and 44 normal tissues (Table 1). Differential expression analysis was performed using the GeneSpring GX software from Agilent Technologies. The volcano plot module was applied, using a fold change $>1.5$ and a $p$-value of $<0.05$. An additional validation step was performed for miR-200b in normal $(n=19)$, DPBC $(n=47)$ and TNBC $(n=21)$ tissues (Table 2$)$, in order to sustain the plasma expression profiling and the TCGA data, displayed as Pirate Plot generated in R programme.

\section{Survival analysis for the TCGA patients}

We extracted the patient survival data from the TCGA clinical information file. In the case of miR-200b, miR-200c, miR-210, and miR-29, the survival was estimated in days from the date of diagnosis until date of last contact. Survival analysis was performed by using Kaplan Meier curves, in the GraphPad Prism program. In addition, we assessed the correlation of miR-200b to
Table 1 TGGA patient cohort characteristics

\begin{tabular}{|c|c|c|}
\hline Demographics & $\operatorname{TNBC}(n=112)$ & $\mathrm{DPBC}(n=358)$ \\
\hline \multicolumn{3}{|l|}{ Sex } \\
\hline Males & 0 & 3 \\
\hline Females & 112 & 355 \\
\hline \multicolumn{3}{|l|}{ Age } \\
\hline Median, Range & $54,29-90$ & $58,28-90$ \\
\hline Median, Range $\widehat{\jmath}$ & - & $68,44-84$ \\
\hline Median, Range $q$ & $54,29-90$ & $58,28-90$ \\
\hline \multicolumn{3}{|l|}{ Menopausal status } \\
\hline Pre-menopausal & 30 & 89 \\
\hline Peri-menopausal & 5 & 16 \\
\hline Post-menopausal & 68 & 225 \\
\hline Unknown, N/A & 9 & 28 \\
\hline \multicolumn{3}{|l|}{ TNM } \\
\hline $\mathrm{T} 1$ & 27 & 110 \\
\hline $\mathrm{T} 2$ & 70 & 189 \\
\hline T3 & 11 & 48 \\
\hline T4 & 4 & 10 \\
\hline Tx & - & 1 \\
\hline NO & 72 & 168 \\
\hline $\mathrm{N} 1$ & 25 & 121 \\
\hline N2 & 11 & 39 \\
\hline N3 & 4 & 25 \\
\hline Nx & - & 5 \\
\hline MO & 95 & 308 \\
\hline Mx & 17 & 50 \\
\hline \multicolumn{3}{|l|}{ Turmor grade } \\
\hline I & 20 & 72 \\
\hline$\|$ & 70 & 195 \\
\hline III & 18 & 82 \\
\hline IV & 1 & 3 \\
\hline X / unknown & 3 & 6 \\
\hline
\end{tabular}

the most relevant metastatic markers, as described in literature $[28,29]$.

\section{Sampling procedures}

The sampling for all biological specimens was done after we received the approval from the Oncology Institute "Prof. Dr. Ion Chiricuta" Ethics Committee and the informed consent form signed by the patient. The patients were diagnosed at the Oncology Institute "Prof. Dr. Ion Chiricuta" in Cluj-Napoca, Romania. The clinical characteristics of patients are presented in Table 3. The blood samples were collected from patients with TNBC or DPBC prior to treatment, between November 2010 and August 2013. In addition, blood samples from eight 
Table 2 Clinical characteristic of patients with TNBC and DNBC patient cohort for PCR-array screening profile and plasma qRT$P C R$ validation lot

\begin{tabular}{|c|c|c|c|c|c|}
\hline & \\
\hline No & TNM stage & Age & No & TNM stage & Age \\
\hline TNBC & & & 20 & T2N2aMx & 48 \\
\hline 1 & T4bN1 M0 & 56 & 21 & $\mathrm{~T} 2 \mathrm{~N} 1 \mathrm{M} 0$ & 64 \\
\hline 2 & T2NOMO & 59 & 22 & T3N1Mx & 63 \\
\hline 3 & T4bN2Mx & 40 & 23 & T2NOMO & 62 \\
\hline 4 & T2N0M0 & 52 & 24 & T4N3bMx. & 70 \\
\hline 5 & T2 N1 Mo & 46 & 25 & T2NOMO & 62 \\
\hline 6 & T2NOMO & 53 & 26 & T3N1aMx & 66 \\
\hline 7 & T2 N1 Mo & 56 & 27 & T1NOMO & 69 \\
\hline 8 & T3 N1 M0 & 46 & 28 & T3N1Mx & 45 \\
\hline 9 & T4bN1 Mo & 57 & 29 & T2 N1 M0 & 44 \\
\hline 10 & T3 N1 M0 & 50 & 30 & T3N1Mx & 36 \\
\hline 11 & T4bN2Mx & 57 & 31 & T2NOMO & 42 \\
\hline 12 & T4bN2M0 & 55 & 32 & T3N0Mx & 47 \\
\hline 13 & T2 N1 Mo & 35 & 33 & T2N1Mx & 47 \\
\hline 14 & T4CN2Mx & 59 & 34 & $\mathrm{~T} 2 \mathrm{~N} 1 \mathrm{M} 0$ & 41 \\
\hline 15 & T2 N1 M0 & 48 & 35 & T4N2Mx & 51 \\
\hline 16 & T4bN1 M0 & 50 & 36 & $\mathrm{~T} 2 \mathrm{~N} 1 \mathrm{M} 0$ & 44 \\
\hline 17 & T2 N1 M0 & 51 & 37 & T4N2Mx & 45 \\
\hline 18 & T3 N1 M0 & 59 & 38 & T3N0Mx & 37 \\
\hline 19 & T3 N1 M0 & 45 & 39 & T4N2Mx & 73 \\
\hline 20 & T4bN1 Mo & 56 & 40 & T3N1Mx & 40 \\
\hline 21 & T3 N1 M0 & 53 & 41 & T4N2Mx & 49 \\
\hline DPBC & & & 42 & T4N1Mx & 56 \\
\hline 1 & T2N1aMx & 59 & 43 & T3N3Mx. & 80 \\
\hline 2 & T2 N1 Mo & 69 & 44 & T3N3Mx. & 49 \\
\hline 3 & T3N1Mx & 60 & 45 & T4N2Mx & 59 \\
\hline 4 & T2N0Mx & 39 & 46 & T3N0Mx & 49 \\
\hline 5 & T4bN3aMx & 73 & 47 & $\mathrm{~T} 2 \mathrm{~N} 1 \mathrm{M} 0$ & 59 \\
\hline
\end{tabular}

T2NOMx 42

T3N1Mx 58

T2 N1 MO 41

T1NOMx 67

T4bN1 M0 66

T3N1Mx 52

T2N2aMx 57

T4bN1 MO 52

T1NOMX 42

T4bN1 MO 38

T2N1Mx 62

T2NOMO 46

T3NOMO 57
Table 2 Clinical characteristic of patients with TNBC and DNBC patient cohort for PCR-array screening profile and plasma qRT$\mathrm{PCR}$ validation lot (Continued)

healthy female controls, free of any chronic diseases, were obtained in the second half of 2013. Sampling for all biological specimens was performed according to Romania's laws and accompanied by an informed consent signed by every donor. The peripheral blood samples were collected in $3 \mathrm{ml}$ tubes with EDTA for plasma isolation, and prepared by centrifuging the blood at $3000 \times \mathrm{rpm}$ for five minutes. The plasma supernatant was carefully removed, placed in $2 \mathrm{ml}$ Eppendorf tubes, and stored at $-80{ }^{\circ} \mathrm{C}$. The qRT-PCR for miRNA-39 was used as quality control for extraction efficiency and as an indicator of miRNA recovery rate from plasma.

miRNA isolation from plasma samples

Before use, plasma samples were thawed for five minutes on ice. Total circulating miRNAs were isolated from a 
Table 3 Clinical characteristic of patients with TNBC and DNBC patient cohort for PCR-array screening profile and plasma qRT$\mathrm{PCR}$ validation lot

\begin{tabular}{lll}
\hline No & TNM stage & Age \\
\hline PCR-array plasma &
\end{tabular}

TNBC

1

2

3

4

5

6

7

8

9

10

11

12

13

14

DPBC

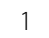

2

3

4

5

6

7

8

9

10

11

12

13

14

qRT-PCR plasma

TNBC

1

2

3
T4bN3M0 58

T2 N1 MO

T3N2M0

T4bN1 Mo

T3 N1 MO

T4bN2M0

T2 N1 MO

T2 N1 MO

T4bN2MO

T2 N1 MO

T2N2Mx

T2 N1 MO

T4CN2Mx

T4bN2M0

T1NOMO

T1 N1 Mo

T2N2Mo

T4bN2Mx

T2NOMO

CT2 N1 MO

T2N2MO

T2N2M0

T4bN2Mx

T4bN2M0

T3 N1 MO

T2N1Mx

T2N1Mo

T2 N1 Mo

T3NOMx

T3 N1 MO

T2NOMO

T1NOMO

T4aNOMO

T2NOMO

T4bN1 Mo

T2NOMO

T2N3cMO
Table 3 Clinical characteristic of patients with TNBC and DNBC patient cohort for PCR-array screening profile and plasma qRTPCR validation lot (Continued)

\begin{tabular}{|c|c|c|}
\hline No & TNM stage & Age \\
\hline 4 & T2 N1 M0 & 57 \\
\hline 5 & $\mathrm{~T} 2 \mathrm{~N} 1 \mathrm{M} 0$ & 46 \\
\hline 6 & T2NOMO & 53 \\
\hline 7 & $\mathrm{CT} 2 \mathrm{~N} 2 \mathrm{MO}$ & 59 \\
\hline 8 & T4bN2M0 & 73 \\
\hline 9 & cT1N0M0 & 70 \\
\hline 10 & T2N2Mx & 49 \\
\hline 11 & cT4bN2M0 & 61 \\
\hline 12 & cT4bN2Mx & 57 \\
\hline 13 & cT2N1Mx & 74 \\
\hline 14 & T2NOMO & 53 \\
\hline 15 & T2NOMO & 34 \\
\hline 16 & $\mathrm{~T} 2 \mathrm{~N} 1 \mathrm{CM} 0$ & 62 \\
\hline 17 & $\mathrm{~T} 4 \mathrm{bN} 2 \mathrm{MO}$ & 46 \\
\hline 18 & T1 N1 M0 & 38 \\
\hline 19 & T3 N1 M0 & 40 \\
\hline 20 & T2 N1 Mo & 35 \\
\hline 21 & T2N0MO & 36 \\
\hline 22 & T2N0MO & 37 \\
\hline 23 & T2NOMO & 34 \\
\hline 24 & T2NOMO & 36 \\
\hline
\end{tabular}

$\begin{array}{ll}\text { T2 N1 M0 } & 54 \\ \text { T2NoMo } & 59 \\ \text { T2 N1 M0 } & 52 \\ \text { T2N0M0 } & 46 \\ \text { T4bN2Mx } & 60 \\ \text { T3N1Mx } & 63 \\ \text { T2N0M0 } & 67 \\ \text { T4bN2M0 } & 53 \\ \text { T3N1Mx } & 43 \\ \text { T2N0M0 } & 51 \\ \text { T2 N1 M0 } & 64 \\ \text { T2N1Mo } & 57 \\ \text { T4bN2M0 } & 45 \\ \text { T3N0Mx } & 69 \\ \text { T2N1Mx } & 52 \\ \text { T2 N1 M0 } & 44 \\ \text { T2 N1 M0 } & 55 \\ \text { T2 N1 M0 } & 62 \\ \text { T1 N1 M0 } & 49 \\ \text { T3N1Mx } & 40\end{array}$


Table 3 Clinical characteristic of patients with TNBC and DNBC patient cohort for PCR-array screening profile and plasma qRT$\mathrm{PCR}$ validation lot (Continued)

\begin{tabular}{lll}
\hline No & TNM stage & Age \\
\hline 21 & T3N0Mx & 45 \\
22 & T3N1Mx & 60 \\
23 & T4N2M0 & 63 \\
24 & T4 N1 M0 & 50 \\
25 & T2N1Mx & 65 \\
26 & T2 N1 M0 & 60 \\
27 & T2NoMo & 44 \\
28 & T4bN2Mo & 47 \\
\hline
\end{tabular}

$200 \mu \mathrm{l}$ plasma aliquot using a commercially available column-based assay, according to the manufacturer's instructions (Qiagen miRNeasy Serum/Plasma Kit). Spike-in control, containing lyophilized C. elegans miR-39 miRNA mimic was added to each sample, used as a PCR normalization control. In the final elution stage, $14 \mu \mathrm{l}$ of RNase-free water were added to the membrane of the MinElute spin column. This was incubated for $1 \mathrm{~min}$ at room temperature and centrifuged at $1200 \mathrm{~g}$ for another minute. The isolated miRNA samples were stored at $20^{\circ} \mathrm{C}$ before processing.

\section{PCR array analysis}

To generate the cDNA, we used the miScript HiSpec Buffer and $2 \mu \mathrm{l}$ of total RNA. The $20 \mu \mathrm{l}$ amplification mixture was incubated at $37^{\circ} \mathrm{C}$ for $60 \mathrm{~min}$, then at $95^{\circ}$ $\mathrm{C}$ for $5 \mathrm{~min}$. The cDNA was then diluted and mixed with the miScript miRNA PCR array kit, containing specific miRNA primers and QuantiTect SYBR Green PCR Master Mix. For the PCR array analysis, we worked with the 96-well Human Breast Cancer miScript miRNA PCR Array (SABiosciences), containing replicates for miRNA reverse transcription control assay (miRTC) and a positive PCR control (PPC). The plate contains probes for 84 miRNAs whose expression is known or expected to be altered in breast cancer. The miScript SYBR Green PCR Kit was used following the manufacturer protocol, with one exception: only half of the cDNA volume was used and therefore $50 \mu \mathrm{l}$ of RNase free water was added at the total volume of the reaction mixture. For the PCR-array determination, the Roche LightCycler 480 instrument was used, following the cycling conditions indicated by the producer.

The miRNA PCR-array data analysis is displayed as fold-change mean for TNBC group, compared with the healthy female controls. For the interpretation of data, we used a web analysis tool provided by Qiagen, USA (https://www.qiagen.com/us/shop/genes-and-pathways/ data-analysis-center-overview-page/), based on the $\Delta \Delta \mathrm{c}_{\mathrm{t}}$ method for the calculation of relative miRNA expression. The normalization was done with the help of the average $\mathrm{Ct}$ value and the reference expression of cel-miR-39, SNORD68, SNORD95, SNORD96A, RUN6-2.

\section{qRT-PCR data validation}

To perform data validation, samples from 28 healthy controls, 24 TNBC and 24 DPBC were analyzed. For the cDNA protocol, we took a total of $50 \mathrm{ng}$ of isolated RNA and mixed it with the Taqman microRNA Reverse Transcription Kit (Cat. No. 4366596, Life Technologies) in a reaction volume of $7.5 \mu \mathrm{l}$. Then the following cycling parameters were utilized: $16{ }^{\circ} \mathrm{C}$ for $30 \mathrm{~min}, 42{ }^{\circ} \mathrm{C}$ for $30 \mathrm{~min}, 85^{\circ} \mathrm{C}$ for $5 \mathrm{~min}$. The qRT-PCR reaction was performed on the ViiA7 instrument (Applied Bio systems) by using $5 \mu \mathrm{l}$ of SsoFast Supermix (Biorad cat no. 172-5230), $4.5 \mu \mathrm{l}$ of $5 \mathrm{X}$ diluted cDNA and $0.5 \mu \mathrm{l}$ of TaqMan Primer. The evaluated miRNAs were: miR-10a, miR-125, miR-193b, miR-200b and miR-489. For data normalization of miRNA expression levels, U6 was used. The same protocol was used for the miR-200b tissue validation. When normalizing this data set, we used U6, RNU48 and miR-16. The qRT-PCR cycle was set at: $98^{\circ}$ $\mathrm{C}$ for $3 \mathrm{~min}, 40$ cycles of $95{ }^{\circ} \mathrm{C}$ for $15 \mathrm{~s}, 60{ }^{\circ} \mathrm{C}$ for $30 \mathrm{~s}$. The data were analysed by applying the $\Delta \Delta \mathrm{Ct}$ method and presented as Pirate Plot using R.

\section{Results \\ Evaluation of altered tissue miRNA pattern in TNBC and DPBC using TCGA data}

The overall survival rates for the TNBC and DPBC patient cohorts are presented in Fig. 1a. TNBC had a lower survival rate than DPBC. No significant difference was found among the patients with metastases versus those without metastases (Fig. 1b-c). When the cases were separated based on the disease stage, we found that there was a statistically significant difference in only one case, namely stage IV TNBC. Therefore, we did not take it into consideration for further analysis. For the rest of the stages, the differences were not statistically significant (Fig. 1d-e).

To delineate specific miRNAs for pathological differentiation like those associated with TNBC and DPBC, we did a profiling analysis using the miRNA expression values from the TCGA database (level 3 accessibility). The extracted data came from 112 TNBC tissue samples, 358 DPBC tissue samples and 44 normal tissue samples. We used a cut-off value of 1.5 for the fold change and of 0.05 for the $p$-value. The comparison between tumors and normal tissue identified 33 down-regulated miRNAs and 138 up-regulated miRNAs in TNBC. Specifically for DPBC, 100 miRNAs were underexpressed and 74 miRNAs were overexpressed. In the case of TNBC versus DPBC, we found 15 
A

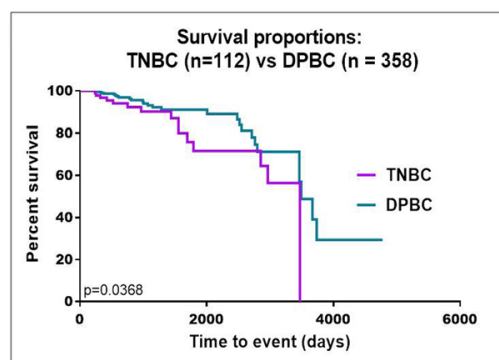

B

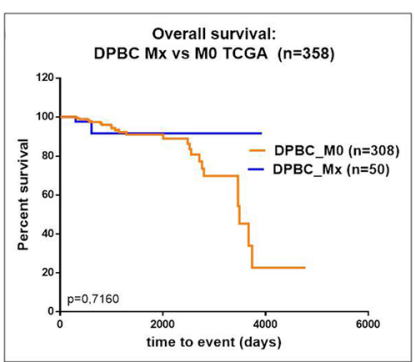

C

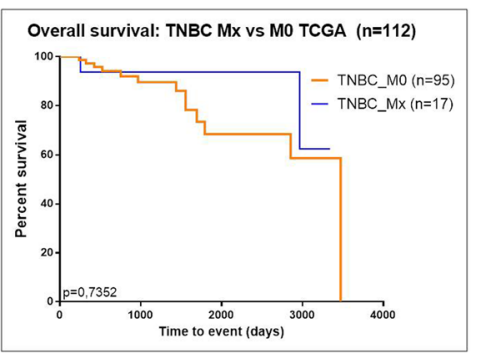

D

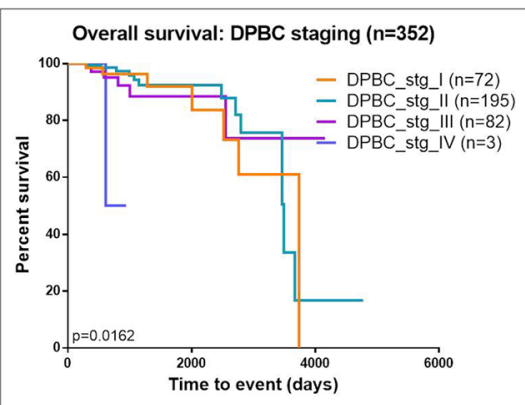

E

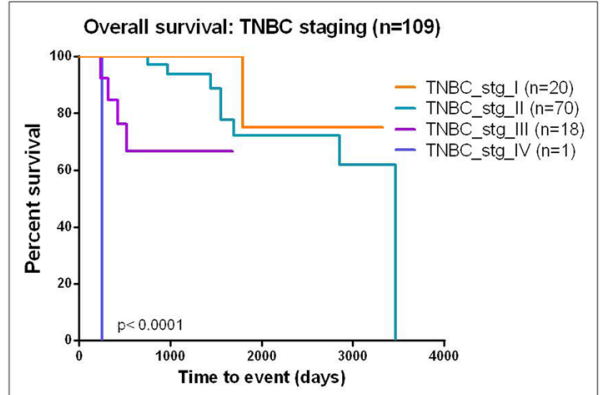

\section{F TCGA down-regulated miRNAs}

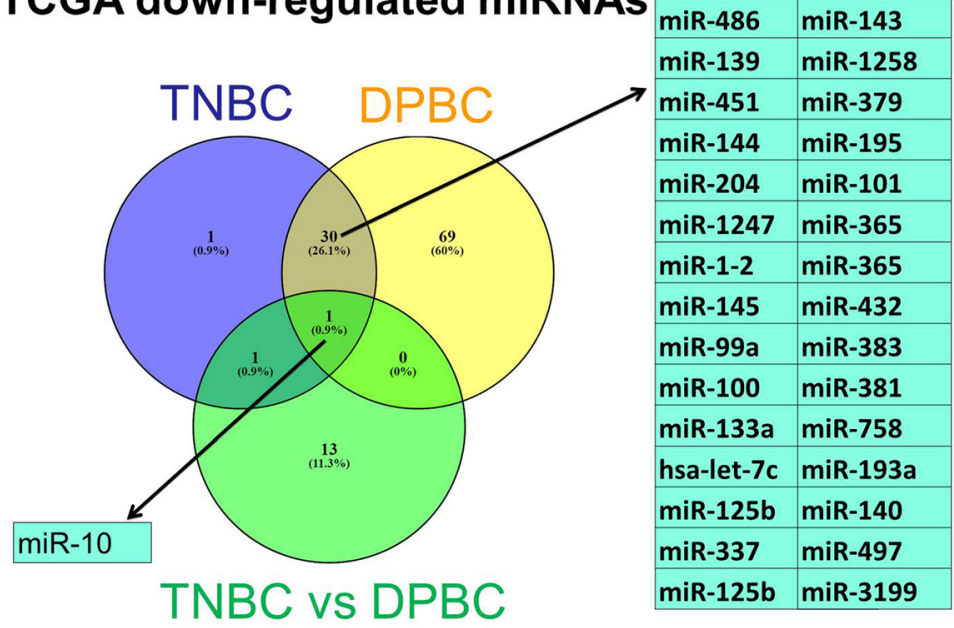

\section{G TCGA up-regulated miRNAs}

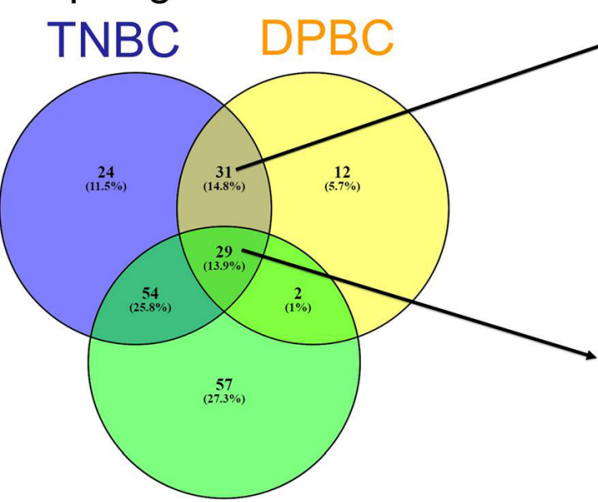

TNBC vs DPBC

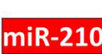

miR-181b-2 miR-142

miR-181b-1 miR-33a

miR-148a miR-301a

miR-3677 miR-130b

miR-106a miR-590

miR-1307 miR-1301

miR-93

miR-340

miR-671

miR-15b

miR-3613

miR-128

miR-937

miR-345

miR-187

miR-940

miR-32

miR-429

miR-200a

miR-183

miR-96

miR-503

miR-33b

miR-200c

miR-200b

miR-196a

miR-21

miR-192

miR-7-1

miR-592

miR-454

miR-182

miR-148b

miR-331

miR-493

miR-760

miR-3065

miR-191

miR-16-1

miR-615

miR-103

miR-92b

miR-3127

miR-3610

miR-15a

miR-107

miR-147b

Fig. 1 (See legend on next page.) 
(See figure on previous page.)

Fig. 1 Evaluation of altered tissue miRNA pattern based on TCGA data. (a) Kaplan-Meier analysis of 112 TNBC and 358 DPBC patients from TCGA database; (b) the analysis of the overall survival rate in TNBC cases with metastases $(n=17)$ versus those without metastases (95); (c) analysis of the overall survival rate in TNBC cases with metastases $(n=17)$ versus those without metastases $(n=95)$, (d) and (e) cumulative disease-free survival separated on staging for TNBC, respectively for DPBC, $(\mathbf{f})$ and $(\mathbf{g})$ Venn diagram, depicting the overlap between the miRNA detected as overexpressed or downregulated in the TNBC versus normal tissue, DPBC versus normal tissue, respectively TNBC versus DPBC patient cohort, based on the TCGA data

downregulated and 142 overexpressed transcripts. Further details on the TGCA data analysis are found in Additional files 1, 2, 3: Table S1-S3. Based on this data, we also constructed heatmaps for the analyzed groups. The aforementioned heatmaps are as follows: Additional file 4: Figure S1 for TNBC vs. normal tissue; Additional file 5: Figure S2 for DPBC vs. normal tissue, and Additional file 6: Figure S3 for TNBC vs. DPBC. A summary of the above mentioned data is presented in Fig. 1f-g, which consists of a list with the miRNA expression profiles common for both $\mathrm{BC}$ subtypes and an intersection profile for the up- or down-regulated miRNAs in the two Her-2- BCs. These results illustrate the miRNAs pattern specific for each $B C$ subtype.

Plasma miRNA profiling in TNBC and DPBC. Validation of the most relevant altered transcripts.

The miRNA profiling study for plasma samples was conducted on a total of 45 patients. The immunohistochemistry (IHC) analysis had previously revealed that 20 cases had TNBC and 14 cases had DPBC. A PCR-array study was performed, based on the SABiosciences technology. The panel contained 84 miRNAs recognized as being involved in $\mathrm{BC}$ development and progression. The data was normalized with the help of cel-miR-39, SNORD68, SNORD95, SNORD96A, RUN6-2. The miRNAs with a $>1.5$-fold expression difference and $p$-value of $<0.05$ were further taken into consideration. Table 4 presents the differentially expressed miRNAs organized as follows: TNBC vs. Control; DPBC vs. control, and TNBC vs. DPBC. In addition, the heatmap for these results can be seen in Additional file 7: Figure S4. Fig. 2a is a Venn diagram summarizing the commonly altered miRNA transcripts in the analyzed groups. In TNBC versus control comparison, twelve miRNAs were differentially expressed (respectively, nine up- regulated and three down-regulated). Five miRNAs were found to be overexpressed characteristically in the DPBC group.

The expression levels of the five most altered miRNAs (miR-10a, miR-125, miR-193b, miR-200b and miR-489) were validated with the help of qRT-PCR in a new patient cohort of 24 TNBC patients, 28 DPBC patients, and 28 healthy individuals. The miRNA expression levels were normalized with U6. All samples were evaluated in duplicate and the geometric mean values were used for data analysis. This resulted in all of the five transcripts being significantly overexpressed in both DPBC and
TNBC (data displayed as Pirate Plot in Fig. 2b), thereby validating the PCR-array data. The ROC (Receiver operating characteristic) was used to test the specificity and sensitivity of miRNA relative expression level in both groups (TNBC and DPBC), as well as to distinguish between plasma samples from $\mathrm{BC}$ patients vs. healthy controls. The ROC curve analysis showed that miR-125b, miR-193b, miR-200b, and miR-489 could serve as potential biomarkers for discriminating TNBC patients from

Table 4 Plasma microRNAs differentially expressed for selected groups (fold change $\leq-1.5$ or $\geq 1.5$, $p$-value $<0.05$ )

\begin{tabular}{|c|c|c|c|}
\hline \multicolumn{4}{|c|}{ TNBC vs ctrl } \\
\hline $\mathrm{A} 12$ & miR-10a-5p & 4.6091 & 0.000083 \\
\hline B02 & miR-125b-5p & 2.5615 & 0.02088 \\
\hline B08 & miR-132-3p & 3.6063 & 0.004549 \\
\hline D02 & miR-193b-3p & 7.5449 & 0.000075 \\
\hline D09 & miR-200b-3p & 4.7585 & 0.003862 \\
\hline D10 & miR-200c-3p & 4.2398 & 0.013366 \\
\hline E07 & miR-210-3p & 4.1482 & 0.001688 \\
\hline G03 & miR-489-3p & 6.7318 & 0.006437 \\
\hline G05 & miR-497-5p & 7.4127 & 0.000067 \\
\hline B06 & miR-130a-3p & -2.1947 & 0.044167 \\
\hline F06 & miR-29a-3p & -1.8771 & 0.039686 \\
\hline F08 & miR-29c-3p & -1.9793 & 0.04623 \\
\hline \multicolumn{4}{|c|}{ DPBC vs ctrl } \\
\hline $\mathrm{A} 12$ & miR-10a-5p & 3.3504 & 0.000725 \\
\hline B02 & miR-125b-5p & 2.2752 & 0.024677 \\
\hline E01 & miR-204-5p & 4.0558 & 0.000389 \\
\hline E07 & miR-210-3p & 3.1667 & 0.018048 \\
\hline G03 & miR-489-3p & 4.9291 & 0.000318 \\
\hline \multicolumn{4}{|c|}{ TNBC vs DPBC } \\
\hline B06 & miR-130a-3p & -2.2079 & 0.043226 \\
\hline C06 & miR-17-5p & -2.0127 & 0.02068 \\
\hline E04 & miR-20a-5p & -1.9896 & 0.032844 \\
\hline E05 & miR-20b-5p & -2.0312 & 0.020571 \\
\hline E10 & miR-22-3p & -3.5484 & 0.009385 \\
\hline F04 & miR-27a-3p & -1.9117 & 0.047502 \\
\hline F06 & miR-29a-3p & -2.1888 & 0.009944 \\
\hline F08 & miR-29c-3p & -2.1302 & 0.018797 \\
\hline G10 & miR-93-5p & -2.1871 & 0.014935 \\
\hline
\end{tabular}


A

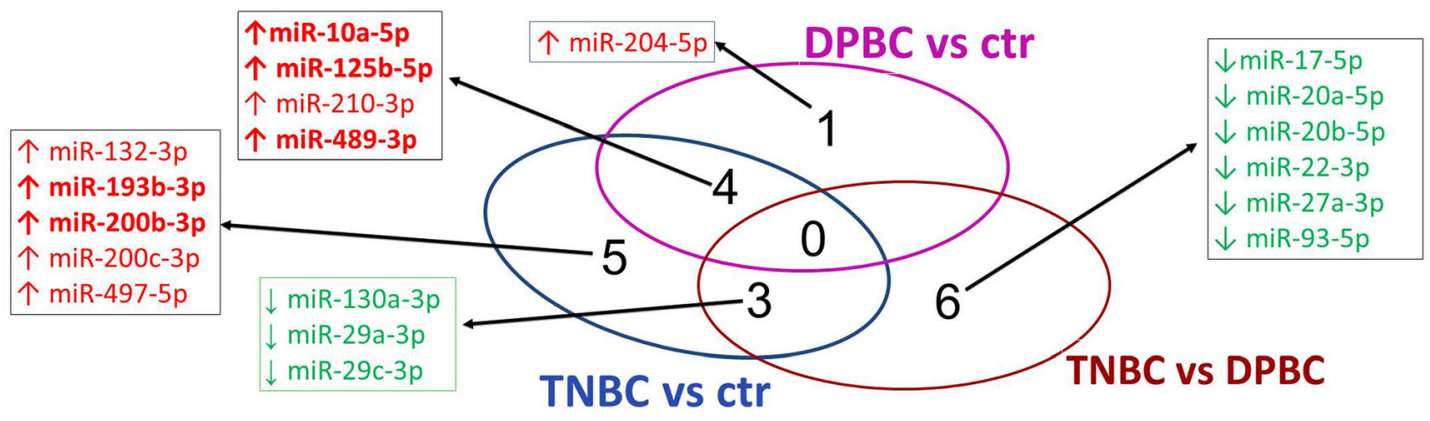

B
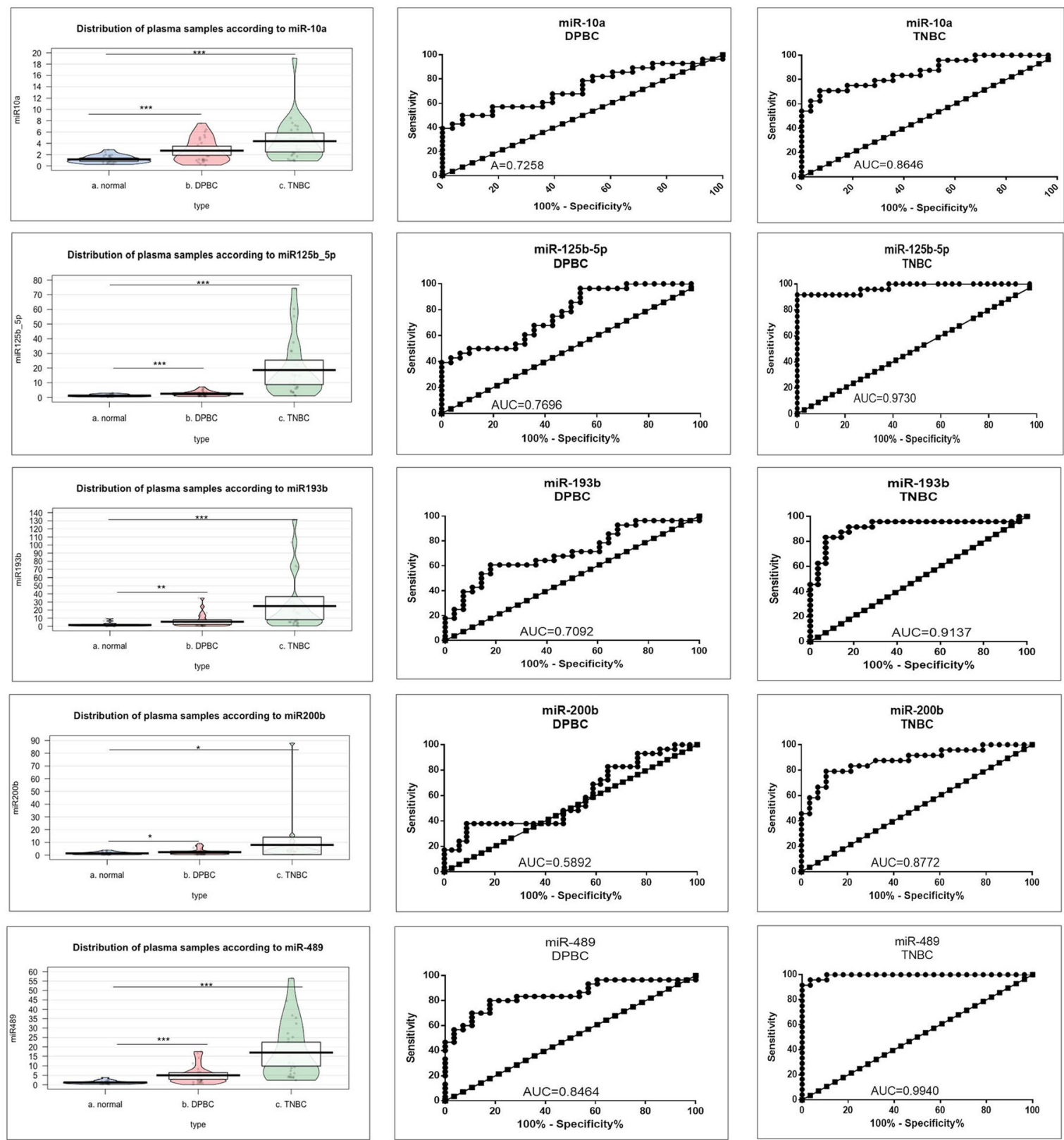

Fig. 2 (See legend on next page.) 
(See figure on previous page.)

Fig. 2 Evaluation of altered plasma miRNA pattern. (a) Venn diagram depicting the overlap between the miRNA detected by PCR-array analysis of selected groups, those displayed in bold are the transcripts selected for validation in a new patient cohort; (b) Expression levels displayed as Pirate Plot for miR-10a, miR-125, miR-193b, miR-200b and miR-489 in the plasma of 28 healthy controls, 28 DPBC patients and 24 TNBC patients. The ROC curves were used to compare the capacity of miRNA to distinguish between the TNBC/DPBC patients and the healthy controls. This was done only for the validated transcript

healthy controls, with AUC (area under the curve) calculated based on ROC curves being 0.9730, 0.9137, 0.8772 and 0.9940 .

\section{Venn diagram analysis of altered miRNA in plasma and the tissue subgroups. Survial rate for the relevant common transctripts}

The altered miRNA expression in plasma and tissue were graphed in the Venn diagram. This was done in order to identify the transcripts with the highest potential of becoming diagnostic/prognostic biomarkers. Fig. 3a shows a list of the miRNA expression profiles common in all groups as well as the overlap between tissue and plasma data. This separates the miRNAs that are specific for each $\mathrm{BC}$ subtype, taking into consideration the same altered expression both in tumor and in plasma. In the case of TNBC, the miRNAs common to the other groups were: miR-200b, miR-200c and miR-210. More exclusively, miR-210 was found to be specific for TNBC while miR-29c can be used to differentiate between TNBC and DPBC.

The clinical relevance of miR-29c, miR-200b, miR-200c and miR-210 was also analyzed by means of Kaplan-Meier survival plots. There was no statistically significant (Fig. 3 B-K) difference between patients with low vs. high expression of these miRNAs. This further proves the complex biology of cancer, which cannot be limited to a single biomarker.

\section{Plasma miRNA biological networks with clinical implication}

The role of miRNAs in $\mathrm{BC}$ pathogenesis is strongly influenced by the complex interactions miRNAs establish with their targeted mRNAs and other miRNAs. Therefore, we decided to construct a miRNA-mRNA interaction network in the Ingenuity Pathway Analysis (IPA) Software. This was done for both $\mathrm{BC}$ subtypes. At the same time, the network revealed the altered pathways specific either for TNBC or for DPBC. The main biological functions affected by the targeted genes were related to cellular development, cell growth and proliferation or invasion (Table 5). In addition, several miRNA were proven to target epithelial to mesenchymal transition (EMT), specifically for the TNBC group.

Using IPA, we were able to generate a miRNA-mRNA interaction network for the miRNAs with altered expression in the plasma from the two HER2- BC patient groups. Fig. 4 represents the miRNA-mRNA interaction network for the TNBC group. The miRNAs that have modified expression values have been color-coded: red for overexpression and green for underexpression. These miRNAs are interconnected with genes involved in apoptosis, cell cycle progression, carcinogenesis and invasion. Therefore, the analysis of biological networks revealed a common miRNA-targeted signature, found to be involved in regulating most of same genes as in the tumor tissue. The TP53 gene is central to this network as it establishes a number of connections with the analyzed miRNAs.

\section{Validation of miR-200b expression level in TNBC and DPBC tissues}

Fig. 5a illustrates the higher expression level of miR-200b in the TNBC tissue $(n=109)$ and DPBC $(n=358)$ tissue compared to the normal tissue $(n=44)$. A second validation step was done for the TNBC $(n=21)$ tissue samples and DPBC $(n=47)$ tissue samples, each respectively compared to normal tissue samples $(n=19)$. This analysis further confirmed the TCGA data, demonstrating that miR-200b is overexpressed in both BC subtypes. Moreover, miR-200b was found to be up-regulated in the plasma from both TNBC and DPBC patients, further validating its potential use as a BC biomarker. The miR-200b targeted genes are presented in Fig. 5b. The analysis was done with the online software TargetScan http://www.targetscan.org/vert_72/. The gene list was then integrated in String https://string-db.org, in order to assess the connection network established between the targeted genes.

\section{Correlation of miR-200b expression levels with metastatic gene markers}

Metastasis formation represents a crucial step in the progression of all cancer types. In $\mathrm{BC}$, each site of metastasis is predicted by set of makers. Therefore, we investigated the relationship between $\mathrm{miR}-200 \mathrm{~b}$ and various metastasis associated genes in the DPBC and TNBC tumors, being selected the specific genes to the brain (BRCA2 and PARP1), to the lungs (TFF1 and RARA), to the liver (CDH2 and ERCC2) and to the bone (MTA1, KPNA2, BMP2, BMP4, VIM, CD44, PTX3, TNFSF11, CTNNB1, NFKB1, VDR). The TCGA data containing the expression levels of mRNA and miRNA was retrieved in the form of separate data matrices from the same online source (UCSC data portal).

Fig. 6a presents the heatmap for the metastasis-related genes in DPBC and TNBC. The correlation between 


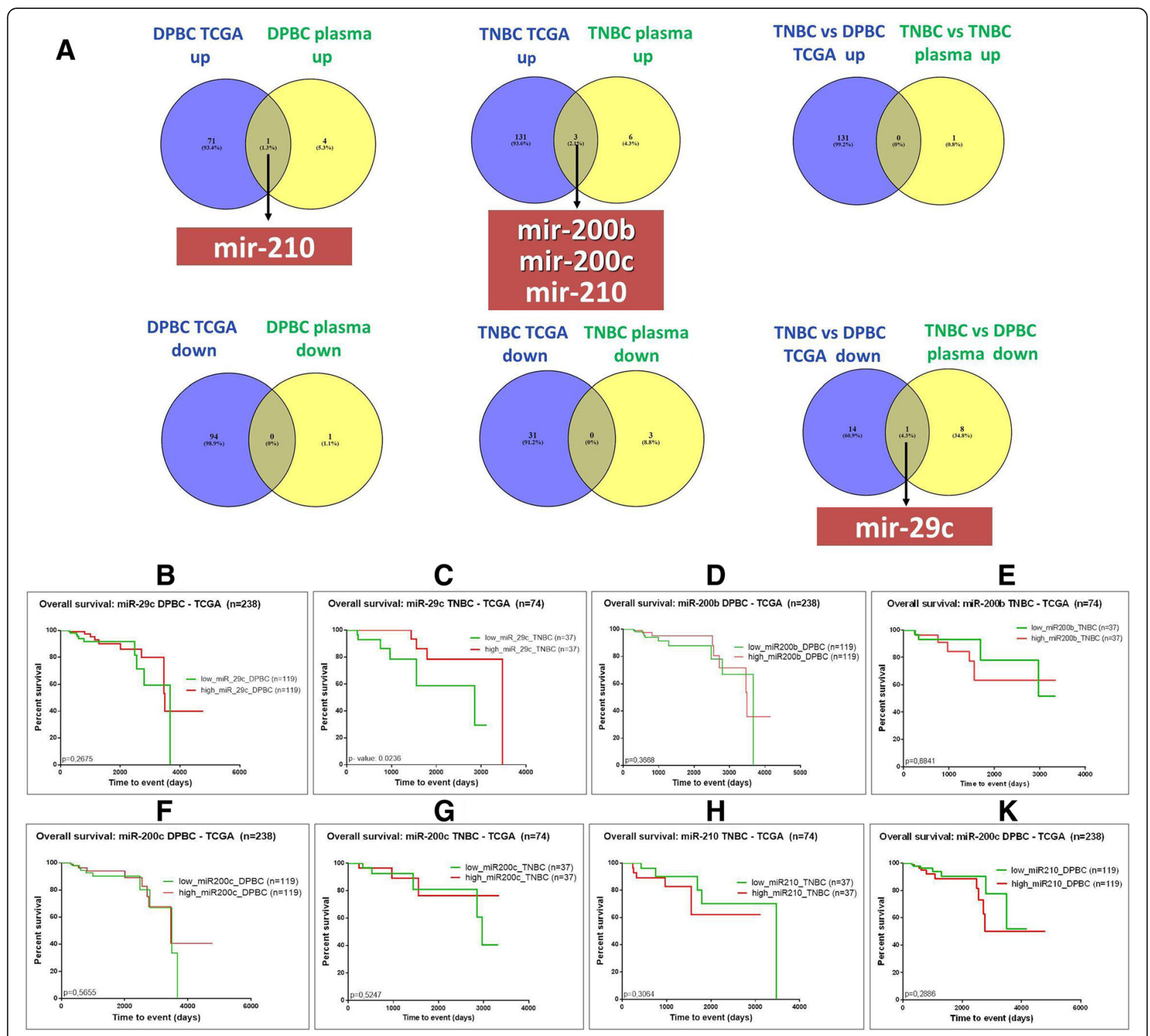

Fig. 3 Survial rate for relevant transctrips. (a) Venny diagram depicting the overlap of the tissue from TCGA evaluation and plasma data, showing the common miRNA with an altered expression level; (b-k) overall survival for high and low expression levels of miR-29, miR-210, miR-200b and miR-200c in the case of TNBC and DPBC groups

miR-200b and these genes is illustrated in Fig. 6b for DPBC and in Fig. 6c for TNBC.

For the DPBC group, we found a statistically significant correlation between miR-200b and 12 genes. A positive correlation was observed for TFF1 and MTA1. A negative correlation was found for $\mathrm{CDH} 2$, BMP2, BMP4, VIM, CD44, PTX3, TNSF11, CTNNB1, NFKB1 and VDR. In the case of the TNBC group, miR-200b was positively correlated with KPNA2 and negatively correlated with TFF1, RARA, BMP2, BMP4, VIM and TNSF11. These data are summarized in Table 6.

\section{Discussion}

Despite the late transition from pan-genomics to the post-genomics era, $\mathrm{BC}$ still remains one of the main causes of cancer related deaths [30]. TNBC is the most aggressive subtype of $\mathrm{BC}$ and it presents the worse clinical outcome among $\mathrm{BC}$ cases [2]. As follows, there is undeniable need for the development of novel diagnostic/prognostic markers that may also constitute therapeutic targets. Over the last few years, different research teams have explored the variation of miRNA profiles in relation to its diagnostic or prognostic potential [11, 21, 24, 31-33]. 
Table 5 miRNAs found to be involved in cellular bio functions cancer

\begin{tabular}{|c|c|c|c|c|c|c|}
\hline & \multicolumn{2}{|l|}{ TNBC } & \multicolumn{2}{|l|}{$\mathrm{DPBC}$} & \multicolumn{2}{|c|}{ TNBC versus DPBC } \\
\hline & $p$-value & Molecules & $p$-value & Molecules & $p$-value & Molecules \\
\hline Cancer & $\begin{array}{l}1.33 E-15- \\
4.83 E-02\end{array}$ & 10 & $\begin{array}{l}3.31 \mathrm{E}-10- \\
3.95 \mathrm{E}-02\end{array}$ & 5 & $\begin{array}{l}4.16 \mathrm{E}-09- \\
4.42 \mathrm{E}-02\end{array}$ & 5 \\
\hline Cellular Development & $\begin{array}{l}4.98 \mathrm{E}-07- \\
4.44 \mathrm{E}-02\end{array}$ & 8 & $\begin{array}{l}1.70 E-04- \\
4.84 E-02\end{array}$ & 4 & $\begin{array}{l}9.03 E-06- \\
4.72 E-02\end{array}$ & 3 \\
\hline Cellular Growth and Proliferation & $\begin{array}{l}4.98 E-07- \\
4.44 E-02\end{array}$ & 8 & $\begin{array}{l}1.54 E-03- \\
3.95 E-02\end{array}$ & 4 & $\begin{array}{l}9.03 E-06- \\
4.72 E-02\end{array}$ & 3 \\
\hline Cell Death and Survival & $\begin{array}{l}1.02 E-04- \\
4.00 E-02\end{array}$ & 7 & $\begin{array}{l}1.80 E-03- \\
8.20 E-03\end{array}$ & 3 & - & - \\
\hline Cellular Movement & $\begin{array}{l}1.42 \mathrm{E}-05- \\
4.34 \mathrm{E}-02\end{array}$ & 6 & $\begin{array}{l}4.88 E-03- \\
3.00 E-02\end{array}$ & 2 & - & - \\
\hline Cell Cycle & - & - & - & - & $\begin{array}{l}5.14 \mathrm{E}-04- \\
1.69 \mathrm{E}-2\end{array}$ & 2 \\
\hline Cell morphology & - & - & - & - & $\begin{array}{l}5.14 \mathrm{E}-04- \\
1.23 \mathrm{E}-02\end{array}$ & 3 \\
\hline
\end{tabular}

Certain miRNAs have a distinct expression profile specific for each BC subtype, which could prove to be a valuable diagnostic/prognostic tool. The bioinformatic analysis of the TCGA dataset is a powerful approach for characterizing miRNA expression patterns in large patients cohorts [27]. This allowed us to perform a comparison between tissue and circulating miRNAs. A partial correlation with the literature data was observed, especially in the case of miR-200 family members. This correlation was confirmed in both tissue and plasma samples. Specific patterns of plasma miRNAs appear to have distinct roles in metastasis. Furthermore, they can be

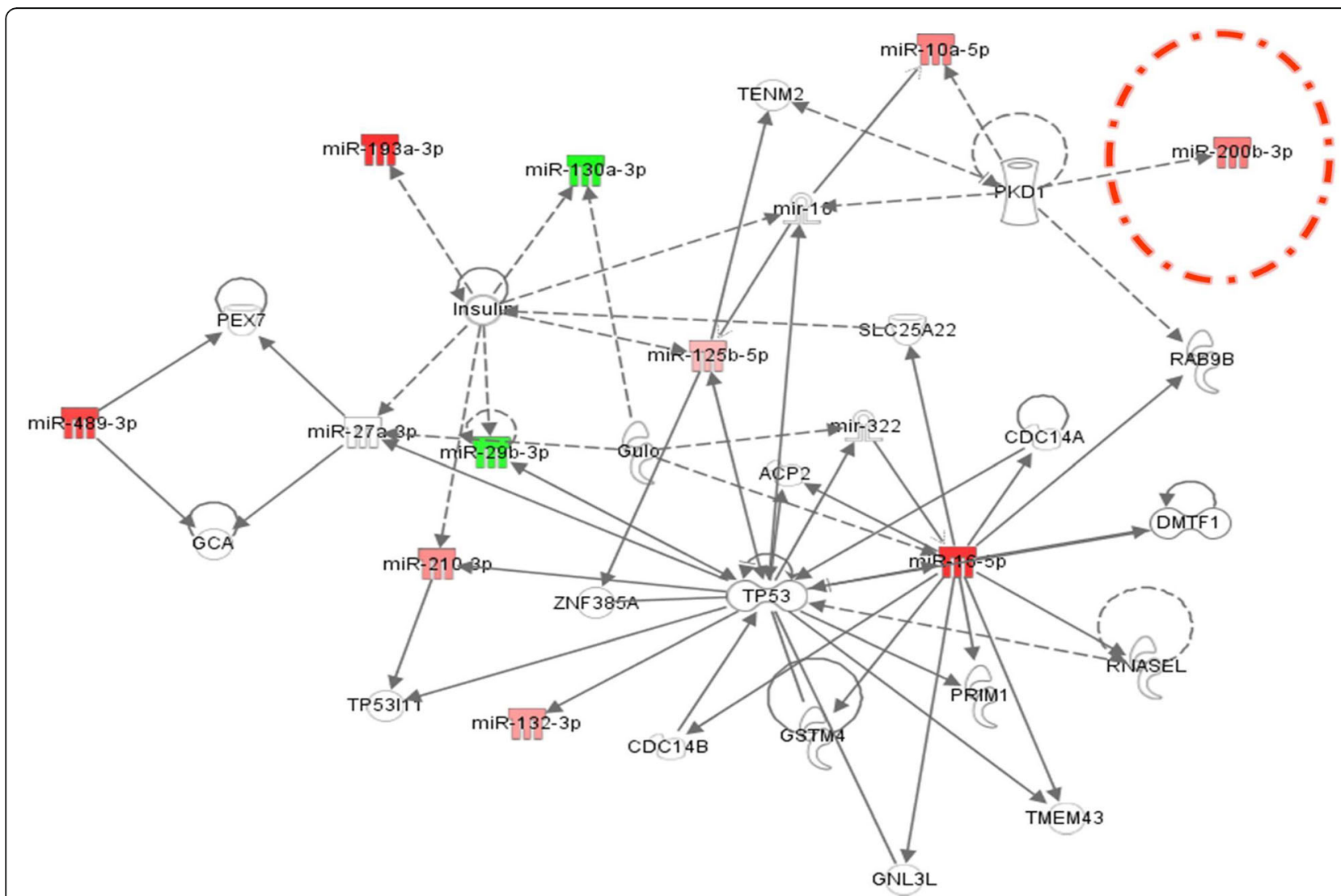

Fig. 4 Network connection between miRNAs found to be involved in regulating the expression of genes related to TNBC (upregulated miRNAs are displayed in red and downregulated miRNAs are displayed in green). The network was generated by using IPA (Ingenuity Pathway Analysis) 

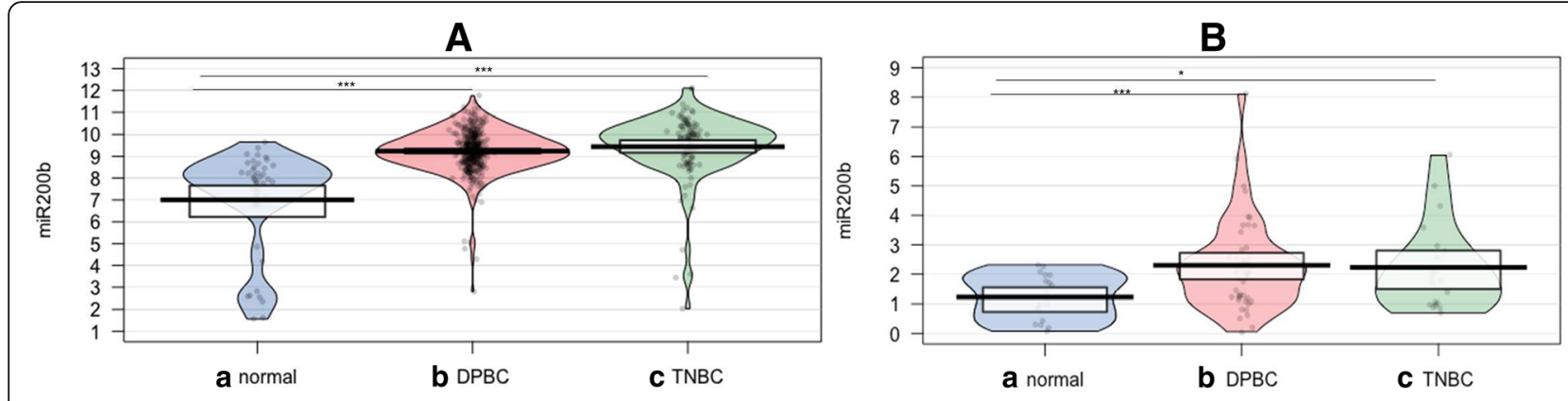

Fig. 5 Validation of miR-200b expression level in TNBC and DPBC tissues. (a) miR-200b expression level in TCGA patient cohort displayed as Pirate Plot, comprising DPBC $(n=352)$ and TNBC $(n=109)$ tissues, reported to normal tissue $(n=44)(\mathbf{b})$ miR-200b expression level on normal $(n=19)$, $\operatorname{DPBC}(n=47)$ and TNBC $(n=21)$ tissues

related to the EMT, to invasion, or to late metastatic events, such as the establishment of metastatic tumors. However, different miRNA profiling studies failed to reach a consensus regarding the local versus systemic levels.

The miR-200 family members are regarded as the main regulators of EMT, invasion and metastasis. Moreover, it was recently discovered that miR-200 s contribute to the angiogenic process by targeting VEGF-A and its receptors $[34,35]$. The inhibition of TGF $\beta$ receptor restores the normal $\mathrm{ZEB} / \mathrm{miR}-200$ balance and it leads to the overexpression of E-cadherin, resulting in reduced tumor dissemination [36]. As follows, miR-200 family is considered an early biomarker of metastasis [37, 38]. Our data supports this role of miR-200 as a general prognostic tool and a specific biomarker of early metastasis. This miRNA can be considered as a single evaluation tool or it can be correlated with the expression level of other coding or non-coding transcripts. Additionally, these other transcripts may function as direct or indirect targets, which can be seen in Fig. 6e.

The EMT process is considered as an efficient strategy adopted by epithelial cancer cells to promote local invasion and dissemination to distant organs [29]. This is supported by our evaluation of the miR-200 as an important metastatic marker, with a particular correlation in lung metastasis. The TFF1 gene was negatively correlated with the expression level for miR-200b in both breast cancer subtypes, meanwhile RARA gene was negatively correlated only in TNBC. We integrated these metastasis associated genes in a complex regulatory network. This could prove to be a useful tool for further experiments studying the mechanism of their action or the way they affect the clinical therapeutic outcomes in these Her-2- BC subtypes (Fig. 6e).

MiR-130 overexpression in breast cancer is related to EMT, invasion and metastasis. In addition, this microRNA is also connected with the downregulation of miR-200 [39, 40]. MiR-130 is known to have an active role in angiogenesis by modulating the expression of VEGF [41]. Another stand-out was miR-22, associated with poor clinical outcomes and the silencing of the TET-miR-200 axis in human breast cancer patients [42]. This microRNA was found to be specific for TNBC, when compared with DPBC.

The miR-29 family members were downregulated in various types of cancers and have been recognized mainly due to their tumor suppressive roles [43]. Lately, these molecules are presented as possible new biomarkers or therapeutic targets in $\mathrm{BC}$, but with no direct implications in the TNBC pathogenesis [44, 45]. What's more, the altered plasma levels of miR-29c and miR-200 were suggested to promote brain metastasis [46]. However, our results showed no correlation between the miR-200 expression level and the evaluated brain metastasis markers (BRCA1 and PARP1).

The miR-210 is another microRNA considered to have an effect over the clinical outcome of cancer patients [47]. The overexpression of this microRNA is correlated with a higher proliferation rate of the cancer cells. For $\mathrm{BC}$ patients, it was associated with an unfavorable prognostic [48], especially for Tamoxifen-treated patients [49]. The miR-210 up-regulation was observed specifically in patients with unresected tumours, lymph node involvement and metastases [50]. Some studies have established a correlation between miR-210 and the therapeutic response to Trastuzumab [50]. The miR-210 expression in TNBC was significantly higher than in DPBC [51]. A meta-analysis revealed that the increased level of miR-210 was related with a reduced overall survival [52]. In our study, the overlap analysis based on the TCGA data confirmed the results from previous studies. The miR-210 expression levels are similar in the plasma as well as the tumor tissue in both TNBC and DPBC.

In order to provide a more comprehensive overview of the interaction established between miRNA and mRNA, we constructed an IPA network. This is a helpful step 

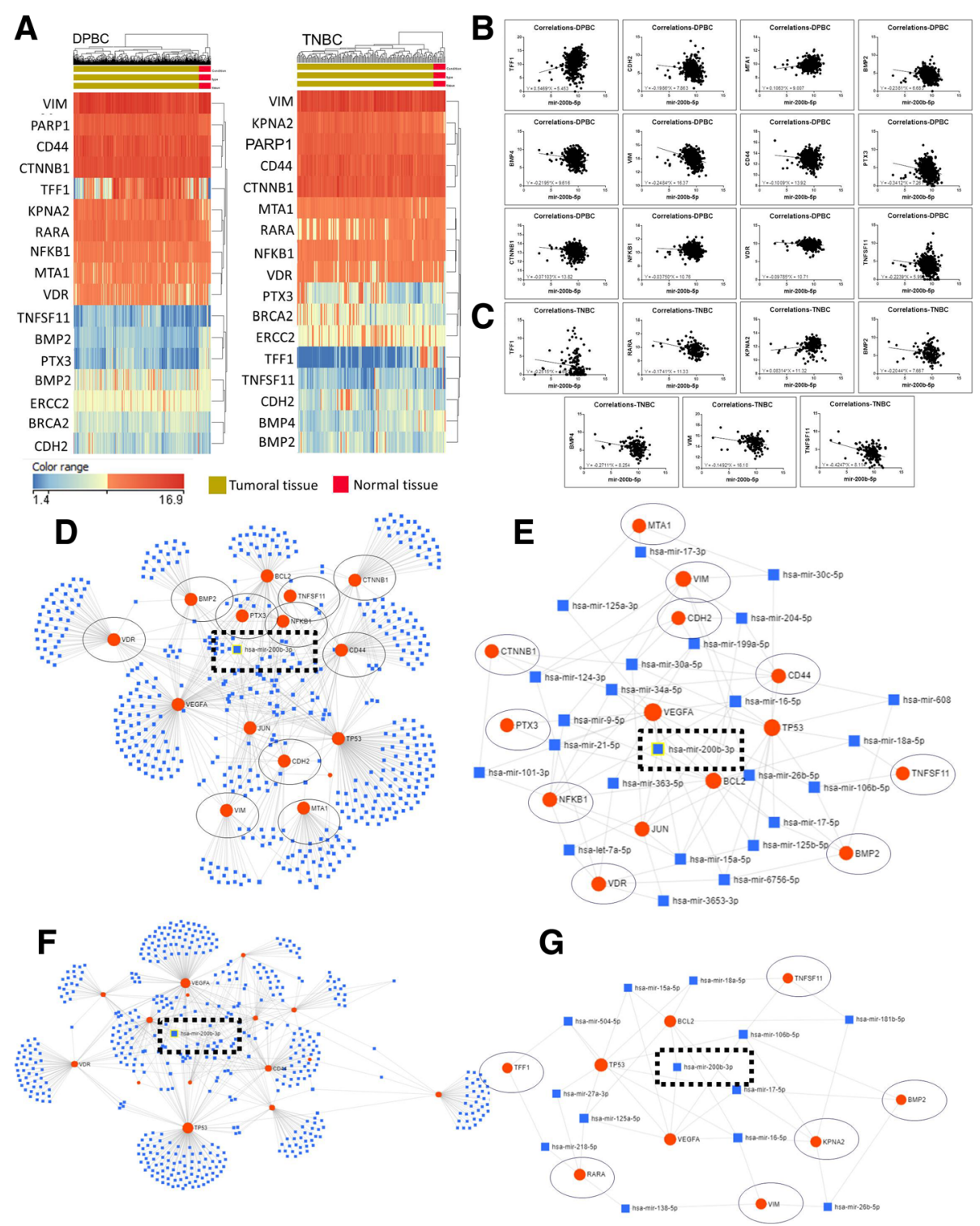

Fig. 6 Correlation between miR-200b expression levels and the most relevant metastatic markers. (a) Heatmap for the metastatic markers in DPBC and TNBC breast cancer, based on TCGA data; (b) and (c) statistically significant correlation of microRNA-200b expression with the expression of the most relevant metastatic genes in DPBC and TNBC cancer (d) summary of metastatic responsive genes negatively or positively correlated with the expression level for miR-200b (e) direct and indirect interconnection of miR-200b with metastatic markers

towards a better understanding of the carcinogenic mechanisms as well as affected cellular pathways in TNBC and DPBC. As it was previously mentioned, EMT is an essential step in the metastatic cascade, because it leads to the activation of invasion and migration (Fig. 4d). Our study revealed a panel of miRNAs related to EMT that could become non-invasive biomarkers.

In this study, further details were revealed regarding the molecular basis of miR-200b involvement in BC metastasis, which can become a future clinical tool for establishing a more accurate prognostic. Our results demonstrated the increased sensibility of combined miRNA signature or miRNA-gene interaction.

The process of implementing a miRNA-based biomarker remains a challenge, the main problem being represented by the small patient cohort and the lack of a standardized method for evaluation. In addition, we need to take into account some of the patient characteristics such as dietary habits, environmental exposure, immune status and age. In this context, one miRNA with an altered expression level does not automatically have an oncogenic or a tumor suppressive role. 
Table 6 Metastatic genes correlated with miR-200b expression gene in DPBC and TNBC TCGA patient

\begin{tabular}{|c|c|c|c|c|c|c|c|}
\hline \multirow[t]{2}{*}{ Metastatic site } & \multirow[t]{2}{*}{ Gene } & \multicolumn{3}{|l|}{$\mathrm{DPBC}$} & \multicolumn{3}{|l|}{ TNBC } \\
\hline & & Pearson $\mathrm{R}$ & 95\% confidence interval & $P$ value & Pearson R & 95\% confidence interval & $P$ value \\
\hline \multirow[t]{2}{*}{ Brain metastasis marker } & BRCA2 & $-0,02537$ & $-0,1161$ to 0,06580 & 0,5745 & 0,08805 & $-0,07530$ to 0,2468 & 0,2760 \\
\hline & PARP1 & 0,02377 & $-0,06739$ to 0,1145 & 0,5988 & 0,1341 & $-0,02884$ to 0,2900 & 0,0963 \\
\hline \multirow[t]{2}{*}{ Lung metastasis marker } & TFF1 & 0,2018 & 0,1129 to 0,2876 & 0,0001 & $-0,1995$ & $-0,3504$ to $-0,03850$ & 0,0128 \\
\hline & RARA & 0,02082 & $-0,07033$ to 0,1116 & 0,6450 & $-0,3054$ & $-0,4456$ to $-0,1506$ & 0,0001 \\
\hline \multirow[t]{2}{*}{ Liver metastasis } & $\mathrm{CDH} 2$ & $-0,1995$ & $-0,2854$ to $-0,1105$ & 0,0001 & $-0,07199$ & $-0,2316$ to 0,09134 & 0,3734 \\
\hline & ERCC2 & 0,05412 & $-0,03709$ to 0,1444 & 0,2308 & 0,003711 & $-0,1587$ to 0,1659 & 0,9634 \\
\hline \multirow[t]{11}{*}{ Bone metastasis } & MTA1 & 0,2114 & 0,1227 to 0,2967 & 0,0001 & 0,1552 & $-0,007210$ to 0,3097 & 0,0538 \\
\hline & KPNA2 & $-0,006807$ & $-0,09777$ to 0,08427 & 0,8803 & 0,1641 & 0,001867 to 0,3179 & 0,0413 \\
\hline & BMP2 & $-0,2626$ & $-0,3454$ to $-0,1758$ & 0,0001 & $-0,2030$ & $-0,3536$ to $-0,04209$ & 0,0113 \\
\hline & BMP4 & $-0,1170$ & $-0,2058$ to $-0,02625$ & 0,0094 & $-0,2244$ & $-0,3730$ to $-0,06443$ & 0,0050 \\
\hline & VIM & $-0,3409$ & $-0,4189$ to $-0,2579$ & 0,0001 & $-0,2438$ & $-0,3906$ to $-0,08490$ & 0,0022 \\
\hline & CD44 & $-0,09716$ & $-0,1865$ to $-0,006196$ & 0,0312 & 0,02089 & $-0,1419$ to 0,1825 & 0,7964 \\
\hline & PTX3 & $-0,2637$ & $-0,3464$ to $-0,1770$ & 0,0001 & $-0,08625$ & $-0,2451$ to 0,07709 & 0,2859 \\
\hline & TNFSF11 & $-0,1752$ & $-0,2620$ to $-0,08554$ & 0,0001 & $-0,2297$ & $-0,3779$ to $-0,07002$ & 0,0040 \\
\hline & CTNNB1 & $-0,1828$ & $-0,2694$ to $-0,09335$ & 0,0001 & $-0,1193$ & $-0,2762$ to 0,04384 & 0,1394 \\
\hline & NFKB1 & $-0,1346$ & $-0,2229$ to $-0,04411$ & 0,0028 & $-0,1166$ & $-0,2737$ to 0,04652 & 0,1484 \\
\hline & VDR & $-0,1421$ & $-0,2301$ to $-0,05171$ & 0,0016 & $-0,1324$ & $-0,2885$ to 0,03051 & 0,1005 \\
\hline
\end{tabular}

\section{Conclusion}

We identified an aberrant miRNA expression pattern in the plasma of TNBC and DPBC patients. Our investigation found several miRNAs deregulated in the plasma of these patients, most of them being common for the HER2- subtypes of breast cancer. The miRNA specific signature for TNBC versus DPBC includes the downregulation of four miRNAs belonging to the miR-17-92 cluster (miR-17-5p, miR-20a, miR-20b, and miR-93), along with other miRNAs, such as miR-130, miR-22 and $\mathrm{miR}-29 \mathrm{a} / \mathrm{c}$. The overlap of circulating plasma and tissue miRNAs emphasizes the important role of miR-200b/c, miR-210 and miR-29c in TNBC tumorigenesis.

The regulatory mechanisms in cancer are more complex than one simple biomarker; miR-200b is a key element for the future answers given to the breast cancer mystery, especially considering that this microRNA is integrated in a regulatory network which acts in conjunction. As follows, not a single node, but the whole network affects the patient prognosis and response to therapy.

Nevertheless, the fluctuating levels of miR-200b provide a deep understanding over some of the mechanisms which drive the metastatic spread from the primary tumour. Controlling these EMT transcripts may increase the survival rate of the TNBC patients, due to their link with metastatic markers that promote cell adhesion, migration, and motility.

Further studies on a larger cohort of patients are needed to validate our findings. Also, much remains to be learned about the application of miRNA-based evaluation of treatment response and the early detection of recurrences.

\section{Additional files}

Additional file 1: Table S1. TCGA tissue microRNAs differentially expressed for TNBC versus normal tissue (fold change $\leq-1.5$ or $\geq 1.5$, $p$-value $<0.05)$. (XLSX $38 \mathrm{~kb}$ )

Additional file 2: Table S2. TCGA tissue microRNAs differentially expressed for DPBC versus normal tissue (fold change $\leq-1.5$ or $\geq 1.5$, $p$-value $<0.05$ ). (XLSX $38 \mathrm{~kb}$ )

Additional file 3: Table S3. TCGA tissue microRNAs differentially expressed for TNBC versus DPBC cancers (fold change $\leq-1.5$ or $\geq 1.5$, $p$-value $<0.05)$. (XLSX $34 \mathrm{~kb})$

Additional file 4: Figure S1. Heatmap for TNBC data from the TCGA data set. (TIFF $424 \mathrm{~kb}$ )

Additional file 5: Figure S2. Heatmap for DPBC data from the TCGA data set. (TIFF $419 \mathrm{~kb}$ )

Additional file 6: Figure S3. Heatmap for TNBC versus DPBC data from the TCGA data set. (TIFF $381 \mathrm{~kb}$ )

Additional file 7: Figure S4. Heatmap for plasma miRNA pattern for TNBC, DPBC and healthy controls. (PNG $14 \mathrm{~kb}$ )

\section{Abbreviations}

AUC: Area under the curve; BC: Breast cancer; cDNA: Complementary DNA; DPBC: Double positive breast cancer patients; EMT: Epithelial to mesenchymal transition; ER: Estrogen receptor; IPA: Ingenuity Pathway Analysis; miRNAs: microRNAs; PR: Progesterone receptor; ROC: Receiving operator curves; TCGA: The Cancer Genome Atlas; TNBC: Triple negative breast cancer patients

\section{Funding}

The present study was financed by the POSCCE (Sectoral Operational Program for Increasing the Economic Competitiveness) 709/2010 grant and by PCE 164/2017, "Addressing the complex exposome profile in hormonedependent cancers of the breast and prostate and its influence on tumoral genome" and PN-III-P1-1.1-TE-2016-2213 (Targeting breast cancer resistance mechanism with combinatorial drug therapy using small molecules and siRNA, in post genomic era). 


\section{Availability of data and materials}

The TCGA material is public available. In the case of plasma PCR-array can be added as the row data and the analysis generate using Qiagen software.

\section{Authors' contributions}

All and CB wrote the paper, AJ, LAP VP and CC performed the experiments, $\mathrm{CB}$ and $\mathrm{RP}$ analyzed the experimental data. GMB and $\mathrm{AE}$ furnished the biological samples and clinical data based. Al, PAC and AP assisted in the preparation of the manuscript and editing. IBN coordinated all the research activity, from the design the experiment to final correction of the manuscript. All authors read and approved the final manuscript.

\section{Authors' information}

Not applicable.

\section{Ethics approval and consent to participate}

All the samples were collected according to the national and international legislation approved by ethical committee of The Oncology Institute "Prof. Dr. Ion Chiricuta". All the patients and the healthy volunteers signed the agreement consent; the samples were stored and processed anonymously in according to the biobanks regulation.

\section{Consent for publication}

Not applicable.

\section{Competing interests}

Authors have no financial and non-financial competing interests be declared.

\section{Publisher's Note}

Springer Nature remains neutral with regard to jurisdictional claims in published maps and institutional affiliations.

\section{Author details}

'Research Center for Functional Genomics, Biomedicine and Translational Medicine, "Iuliu Hatieganu" University of Medicine and Pharmacy, Cluj-Napoca, Romania. ${ }^{2}$ Department of Senology, The Oncology Institute "Prof. Dr. Ion Chiricuta", Cluj-Napoca, Romania. ${ }^{3}$ Department of Analytical Chemistry, Faculty of Pharmacy, "Iuliu Hatieganu" University of Medicine and Pharmacy, Cluj-Napoca, Romania. ${ }^{4}$ MedFuture Research Center for Advanced Medicine, "Iuliu Hatieganu" University of Medicine and Pharmacy, Cluj-Napoca, Romania. ${ }^{5}$ Department of Surgery, The Oncology Institute "Prof. Dr. Ion Chiricuta", Cluj-Napoca, Romania. 'Department of Surgical Oncology and Gynecological Oncology, University of Medicine and Pharmacy luliu Hatieganu, Cluj-Napoca, Romania. ${ }^{7}$ National Cancer Research Centre, Istituto Tumori G Paolo II, Bari, Italy. ${ }^{8}$ Department of Functional Genomics and Experimental Pathology, The Oncology Institute "Prof. Dr. Ion Chiricuta", Cluj-Napoca, Romania.

Received: 1 June 2018 Accepted: 28 September 2018

\section{Published online: 20 October 2018}

\section{References}

1. Ferlay J, Soerjomataram I, Dikshit R, Eser S, Mathers C, Rebelo M, Parkin DM, Forman D, Bray F. Cancer incidence and mortality worldwide: sources, methods and major patterns in GLOBOCAN 2012. Int J Cancer. 2015;136: E359-86. https://doi.org/10.1002/ijc.29210.

2. Chiorean $R$, Braicu C, Berindan-Neagoe I. Another review on triple negative breast cancer. Are we on the right way towards the exit from the labyrinth? Breast. 2013;22:1026-33. https://doi.org/10.1016/j.breast.2013.08.007.

3. Eastlack SC, Alahari SK. MicroRNA and breast Cancer: understanding pathogenesis, improving management. Noncoding RNA. 2015;1:17-43. https://doi.org/10.3390/ncrna1010017

4. Gasparini P, Cascione L, Fassan M, Lovat F, Guler G, Balci S, Irkkan C, Morrison C, Croce CM, Shapiro CL, Huebner K. microRNA expression profiling identifies a four microRNA signature as a novel diagnostic and prognostic biomarker in triple negative breast cancers. Oncotarget. 2014;5:1174-84.

5. Jiang HL, Sun HF, Gao SP, Li LD, Hu X, Wu J, Jin W. Loss of RAB1B promotes triple-negative breast cancer metastasis by activating TGF-beta/SMAD signaling. Oncotarget. 2015.
6. Braicu C, Chiorean R, Irimie A, Chira S, Tomuleasa C, Neagoe E, Paradiso A, Achimas-Cadariu P, Lazar V, Berindan-Neagoe I. Novel insight into triplenegative breast cancers, the emerging role of angiogenesis, and antiangiogenic therapy. Expert Rev Mol Med. 2016;18:e18. https://doi.org/10. 1017/erm.2016.17.

7. Foroni C, Broggini M, Generali D, Damia G. Epithelial-mesenchymal transition and breast cancer: role, molecular mechanisms and clinical impact. Cancer Treat Rev. 2012;38:689-97. https://doi.org/10.1016/j.ctrv. 2011.11.001.

8. Irimie Al, Braicu C, Cojocneanu-Petric R, Berindan-Neagoe I, Campian RS. Novel technologies for oral squamous carcinoma biomarkers in diagnostics and prognostics. Acta Odontol Scand. 2015;73:161-8. https://doi.org/10. 3109/00016357.2014.986754.

9. D'Ippolito E, lorio MV. MicroRNAs and triple negative breast cancer. Int J Mol Sci. 2013;14:22202-20. https://doi.org/10.3390/ijms141122202.

10. Braicu C, Calin GA, Berindan-Neagoe I. MicroRNAs and cancer therapy from bystanders to major players. Curr Med Chem. 2013;20:3561-73.

11. Braicu C, Cojocneanu-Petric R, Chira S, Truta A, Floares A, Petrut B, AchimasCadariu P, Berindan-Neagoe I. Clinical and pathological implications of miRNA in bladder cancer. Int J Nanomedicine. 2015;10:791-800. https:/doi.org/10. 2147/ijn.s72904.

12. Calin GA, Croce CM. MicroRNA signatures in human cancers. Nat Rev Cancer. 2006;6:857-66. https://doi.org/10.1038/nrc1997.

13. Gotte M. MicroRNAs in breast cancer pathogenesis. Minerva Ginecol. 2010; 62:559-71.

14. Volinia S, Galasso M, Sana ME, Wise TF, Palatini J, Huebner K, Croce CM. Breast cancer signatures for invasiveness and prognosis defined by deep sequencing of microRNA. Proc Natl Acad Sci U S A. 2012;109:3024-9. https://doi.org/10.1073/pnas.1200010109.

15. Ling H, Vincent K, Pichler M, Fodde R, Berindan-Neagoe I, Slack FJ, Calin GA. Junk DNA and the long non-coding RNA twist in cancer genetics. Oncogene. 2015. https://doi.org/10.1038/onc.2014.456.

16. Braicu C, Catana C, Calin GA, Berindan-Neagoe I. NCRNA combined therapy as future treatment option for cancer. Curr Pharm Des. 2014;20:6565-74.

17. Chang HT, Li SC, Ho MR, Pan HW, Ger LP, Hu LY, Yu SY, Li WH, Tsai KW. Comprehensive analysis of microRNAs in breast cancer. BMC Genomics. 2012;13(Suppl 7):S18. https://doi.org/10.1186/1471-2164-13-S7-S18.

18. Redis RS, Berindan-Neagoe I, Pop VI, Calin GA. Non-coding RNAs as theranostics in human cancers. J Cell Biochem. 2012;113:1451-9. https://doi. org/10.1002/jcb.24038.

19. Schou JV, Johansen JS, Nielsen D, Rossi S. Circulating microRNAs as prognostic and predictive biomarkers in patients with colorectal Cancer. Noncoding RNA. 2016;2. https://doi.org/10.3390/ncrna2020005.

20. Kosaka N, Iguchi H, Ochiya T. Circulating microRNA in body fluid: a new potential biomarker for cancer diagnosis and prognosis. Cancer Sci. 2010; 101:2087-92. https://doi.org/10.1111/j.1349-7006.2010.01650.x.

21. Berindan-Neagoe I, Monroig Pdel C, Pasculli B, Calin GA. MicroRNAome genome: a treasure for cancer diagnosis and therapy. CA Cancer J Clin. 2014;64:311-36. https://doi.org/10.3322/caac.21244.

22. Berindan-Neagoe I, Calin GA. Molecular pathways: microRNAs, cancer cells, and microenvironment. Clin Cancer Res. 2014;20:6247-53. https://doi.org/10. 1158/1078-0432.ccr-13-2500.

23. Tomuleasa C, Braicu C, Irimie A, Craciun L, Berindan-Neagoe I. Nanopharmacology in translational hematology and oncology. Int J Nanomedicine. 2014;9:3465-79. https://doi.org/10.2147/ijn.s60488.

24. Catana CS, Pichler M, Giannelli G, Mader RM, Berindan-Neagoe I. Non-coding RNAs, the Trojan horse in two-way communication between tumor and stroma in colorectal and hepatocellular carcinoma. Oncotarget. 2017:8:29519-34. https://doi.org/10.18632/oncotarget.15706.

25. Redis RS, Sieuwerts AM, Look MP, Tudoran O, Ivan C, Spizzo R, Zhang $X$, de Weerd $V$, Shimizu $M$, Ling $H$, Buiga $R$, Pop $V$, Irimie $A$, et al. CCAT2, a novel long non-coding RNA in breast cancer: expression study and clinical correlations. Oncotarget. 2013;4:1748-62. https://doi. org/10.18632/oncotarget.1292.

26. Irimie Al, Zimta AA, Ciocan C, Mehterov N, Dudea D, Braicu C, BerindanNeagoe I. The unforeseen non-coding RNAs in head and neck Cancer. Genes (Basel). 2018;9. https://doi.org/10.3390/genes9030134.

27. Chu A, Robertson G, Brooks D, Mungall AJ, Birol I, Coope R, Ma Y, Jones S, Marra MA. Large-scale profiling of microRNAs for the Cancer genome atlas. Nucleic Acids Res. 2016;44:e3. https://doi.org/10.1093/ nar/gkv808. 
28. Klimov S, Rida PC, Aleskandarany MA, Green AR, Ellis IO, Janssen EA, Rakha EA, Aneja R. Novel immunohistochemistry-based signatures to predict metastatic site of triple-negative breast cancers. Br J Cancer. 2017;117:826-34. https:/doi. org/10.1038/bjc.2017.224.

29. Scimeca M, Antonacci C, Toschi N, Giannini E, Bonfiglio R, Buonomo CO, Pistolese CA, Tarantino U, Bonanno E. Breast osteoblast-like cells: a reliable early marker for bone metastases from breast Cancer. Clin Breast Cancer. 2018;18:e659-e69. https://doi.org/10.1016/j.clbc.2017.11.020.

30. Huntsman DG, Ladanyi M. The molecular pathology of cancer: from pan-genomics to post-genomics. J Pathol. 2018;244:509-11. https://doi.org/ 10.1002/path.5057.

31. van Schooneveld E, Wouters MC, Van der Auwera I, Peeters DJ, Wildiers $H$, Van Dam PA, Vergote I, Vermeulen PB, Dirix LY, Van Laere SJ. Expression profiling of cancerous and normal breast tissues identifies microRNAs that are differentially expressed in serum from patients with (metastatic) breast cancer and healthy volunteers. Breast Cancer Res. 2012;14:R34. https://doi. org/10.1186/bcr3127.

32. Conger AK, Martin EC, Yan TJ, Rhodes LV, Hoang VT, La J, Anbalagan M, Burks HE, Rowan BG, Nephew KP, Collins-Burow BM, Burow ME. Argonaute 2 expression correlates with a luminal B breast Cancer subtype and induces estrogen receptor alpha isoform variation. Noncoding RNA. 2016;2. https:// doi.org/10.3390/ncrna2030008.

33. Krutilina R, Sun W, Sethuraman A, Brown M, Seagroves TN, Pfeffer LM, Ignatova T, Fan M. MicroRNA-18a inhibits hypoxia-inducible factor $1 a$ activity and lung metastasis in basal breast cancers. Breast Cancer Research : BCR. 2014;16:R78. https://doi.org/10.1186/bcr3693.

34. Zhang HF, Xu LY, Li EM. A family of pleiotropically acting microRNAs in cancer progression, miR-200: potential cancer therapeutic targets. Curr Pharm Des. 2014;20:1896-903.

35. Braicu C, Tudoran O, Balacescu L, Catana C, Neagoe E, Berindan-Neagoe I, lonescu C. The significance of PDGF expression in serum of colorectal carcinoma patients--correlation with Duke's classification. Can PDGF become a potential biomarker? Chirurgia (Bucur). 2013;108:849-54.

36. Truong HH, Xiong J, Ghotra VP, Nirmala E, Haazen L, Le Devedec SE, Balcioglu HE, He S, Snaar-Jagalska BE, Vreugdenhil E, Meerman JH, van de Water B, Danen EH. Beta1 integrin inhibition elicits a prometastatic switch through the TGFbeta-miR-200-ZEB network in E-cadherin-positive triplenegative breast cancer. Sci Signal. 2014;7:ra15. https://doi.org/10.1126/ scisignal.2004751.

37. Madhavan D, Peng C, Wallwiener M, Zucknick M, Nees J, Schott S, Rudolph A, Riethdorf S, Trumpp A, Pantel K, Sohn C, Chang-Claude J, Schneeweiss A, et al. Circulating miRNAs with prognostic value in metastatic breast cancer and for early detection of metastasis. Carcinogenesis. 2016. https://doi.org/ 10.1093/carcin/bgw008.

38. Zhang G, Zhang W, Li B, Stringer-Reasor E, Chu C, Sun L, Bae S, Chen D, Wei S, Jiao K, Yang W-H, Cui R, Liu R, et al. MicroRNA-200C and microRNA- 141 are regulated by a FOXP3-KAT2B axis and associated with tumor metastasis in breast cancer. Breast Cancer Res : BCR. 2017; 19: 73. doi: https://doi.org/ 10.1186/s13058-017-0858-x

39. Lopez-Serra P, Esteller M. DNA methylation-associated silencing of tumorsuppressor microRNAs in cancer. Oncogene. 2012;31:1609-22. https://doi. org/10.1038/onc.2011.354.

40. Burk U, Schubert J, Wellner U, Schmalhofer O, Vincan E, Spaderna S, Brabletz T. A reciprocal repression between ZEB1 and members of the miR-200 family promotes EMT and invasion in cancer cells. EMBO Rep. 2008;9:582-9. https://doi.org/10.1038/embor.2008.74.

41. Chen Y, Gorski DH. Regulation of angiogenesis through a microRNA (miR-130a) that down-regulates antiangiogenic homeobox genes GAX and HOXA5. Blood. 2008:111:1217-26. https://doi.org/10.1182/blood-2007-07-104133.

42. Song SJ, Pandolfi PP. miR-22 in tumorigenesis. Cell Cycle. 2014;13:11-2. https://doi.org/10.4161/cc.27027.

43. Wu Z, Huang X, Huang X, Zou Q, Guo Y. The inhibitory role of Mir-29 in growth of breast cancer cells. J Exp Clin Cancer Res. 2013;32:98. https://doi. org/10.1186/1756-9966-32-98.

44. Jiang $H$, Zhang $G, W u J H$, Jiang CP. Diverse roles of miR-29 in cancer (review). Oncol Rep. 2014;31:1509-16. https://doi.org/10.3892/or.2014.3036.

45. Cochrane DR, Jacobsen BM, Connaghan KD, Howe EN, Bain DL, Richer JK. Progestin regulated miRNAs that mediate progesterone receptor action in breast cancer. Mol Cell Endocrinol. 2012;355:15-24. https://doi.org/10.1016/j. mce.2011.12.020.
46. Alsidawi S, Malek E, Driscoll JJ. MicroRNAs in brain metastases: potential role as diagnostics and therapeutics. Int J Mol Sci. 2014;15:10508-26. https://doi. org/10.3390/ijms150610508.

47. Yang W, Wei J, Sun T, Liu F. Effects of knockdown of miR-210 in combination with ionizing radiation on human hepatoma xenograft in nude mice. Radiat Oncol. 2013;8:102. https://doi.org/10.1186/1748-717X-8-102.

48. Tang Y, Zhou X, Ji J, Chen L, Cao J, Luo J, Zhang S. High expression levels of miR-21 and miR-210 predict unfavorable survival in breast cancer: a systemic review and meta-analysis. Int J Biol Markers. 2015;30:e347-58. https://doi.org/10.5301/jbm.5000160.

49. Hong L, Yang J, Han Y, Lu Q, Cao J, Syed L. High expression of miR-210 predicts poor survival in patients with breast cancer: a meta-analysis. Gene. 2012;507:135-8. https://doi.org/10.1016/j.gene.2012.07.025.

50. Jung EJ, Santarpia L, Kim J, Esteva FJ, Moretti E, Buzdar AU, Di Leo A, Le XF, Bast RC, Jr., Park ST, Pusztai L, Calin GA. Plasma microRNA 210 levels correlate with sensitivity to trastuzumab and tumor presence in breast cancer patients. Cancer 2012; 118: 2603-2614. doi: https://doi.org/10.1002/cncr.26565.

51. Toyama T, Kondo N, Endo Y, Sugiura H, Yoshimoto N, Iwasa M, Takahashi S, Fujii $Y$, Yamashita $H$. High expression of microRNA-210 is an independent factor indicating a poor prognosis in Japanese triplenegative breast cancer patients. Jpn J Clin Oncol. 2012;42:256-63. https://doi.org/10.1093/jjco/hys001.

52. Lu L, Mao X, Shi P, He B, Xu K, Zhang S, Wang J. MicroRNAs in the prognosis of triple-negative breast cancer: a systematic review and metaanalysis. Medicine (Baltimore). 2017;96:e7085. https://doi.org/10.1097/md. 0000000000007085 .

\section{Ready to submit your research? Choose BMC and benefit from:}

- fast, convenient online submission

- thorough peer review by experienced researchers in your field

- rapid publication on acceptance

- support for research data, including large and complex data types

- gold Open Access which fosters wider collaboration and increased citations

- maximum visibility for your research: over $100 \mathrm{M}$ website views per year

At BMC, research is always in progress.

Learn more biomedcentral.com/submissions 